\title{
Time-history Analysis of a New Assembly Frame with Steel- concrete Composite Lattice Column
}

\author{
Yafei Zhao ${ }^{1}$, Xiaotong Peng ${ }^{1,}{ }^{*}$, Jie Man ${ }^{3}$, Chen Lin $^{2}$ and Xu Zhang ${ }^{1}$ \\ ${ }^{1}$ School of Civil Engineering and Architecture, University of Jinan, Jinan, Shan Dong, China \\ ${ }^{2}$ School of Architecture and Landscape Design, Shandong University of Art \& Design, Jinan, Shan Dong, China \\ ${ }^{3}$ Shandong Greenland Spring Holding Group, Jinan, Shan Dong, China
}

\begin{abstract}
A new assembly steel-concrete composite lattice column frame (SLCF) was proposed as a solution for prefabricated steel structure residential. In order to study the seismic performance of SLCF, a non-linear finite element model under bidirectional ground motion was established by using Sap2000. Based on that, the model of SCLF, reinforced concrete structure and steel frame structure was compared. The results indicate that SCLF has the better strength, lateral stiffness and energy dissipation capacity.
\end{abstract}

\section{Introduction}

Prefabricated steel structure residential has some problems, such as small use space, inflexible structure arrangement, and difficult prefabrication of components [1-2]. A new assembly steel-concrete composite lattice column frame (SLCF) system was proposed as a solution for prefabricated steel structure residential. In this system, the composite lattice column is formed by connecting the concrete filled steel tube with lace plates.

Some scholars have studied lattice columns. Libove [3] studied the buckling performance of rigidly connected steel lattice columns. The results show that the steel lattice columns are affected by the initial bending greatly. The single-limb column is the main vertical member of the steel lattice column. The connection of the components will affect the buckling performance of the column. Kawano A [4] researched the seismic performance of concrete filled steel tube lattice columns. The results show that the structure has better hysteretic behaviour and stiffness. Japanese scholar Kawano et al. [5-8] studied the seismic performance of a new steel frame system with concrete filled steel tube lattice columns. The research shows that this new system has good seismic performance.

Due to the diversity and complexity of the problems involved, the research results of steel-concrete lattice column frame were few. Therefore, it is of great significance to research SCLF's seismic performance.

\section{Design of a new assembly steel- concrete composite lattice column frame}

SLCF is composed of steel-concrete composite lattice column, H-shaped steel beam and composite floor with profiled steel plate, as shown in Figure 1.

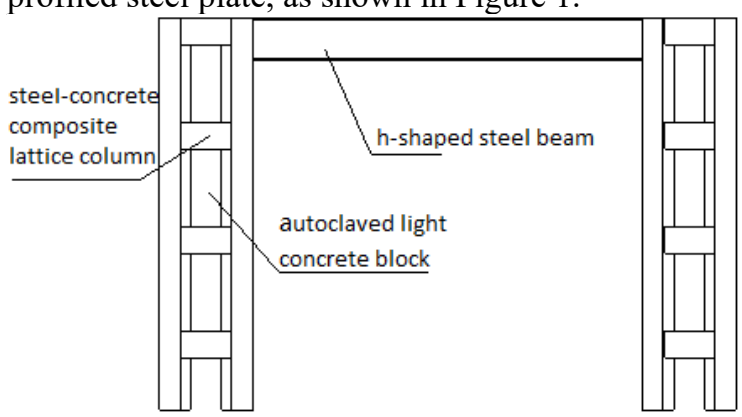

Fig. 1. SLCF

\section{Finite element simulations}

\subsection{Establishment of finite element models}

In this paper, the SLCF model of equivalent steelconcrete composite lattice columns was established by finite element analysis software SAP2000. The steel members in SLCF system all adopt Q345 steel, with yield strength of $345 \mathrm{~N} / \mathrm{mm}^{2}$, elastic modulus of 206000 $\mathrm{N} / \mathrm{mm}^{2}$, and Poisson ratio of 0.3 .

Four sets of models are designed, which are steel frame - core tube structure (SS0), concrete-core tube structure (SR0), steel composite lattice column frame (S1) and SLCF (S2). The material selection of concrete and reinforcement is the same as that of frame columns and inner concrete. The plane layout chart and non-linear finite element model are showed in figure 2-3.

\footnotetext{
$\overline{\text { * Corresponding author: pengxito@163.com }}$
} 


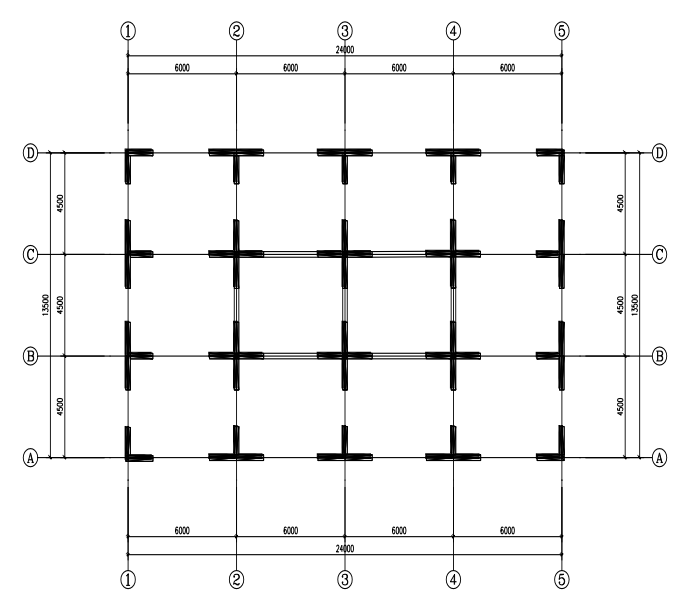

Fig. 2. Plane layout

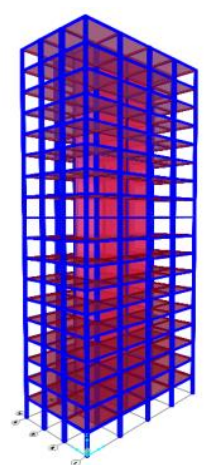

Fig. 3. Non-linear finite element model

\subsection{Time-history analysis of new assembly steel-concrete composite lattice column frame}

In order to understand the internal response of SLCF under seismic action, the non-linear characteristics of SLCF are analysed. According to the Current China Seismic Design Code, seismic waves are selected according to the actual site type and classification of design earthquake. As the code requires that the number of seismic waves should not be less than 23 of the total seismic waves, el-Centro, Taft and Lanzhou artificial waves are selected. See Figure 4-6 for time-history curves of acceleration.

The story displacement, top displacement and vertex acceleration by the four groups of models were compared. The time-history response of the structure under the earthquake action was analysed.

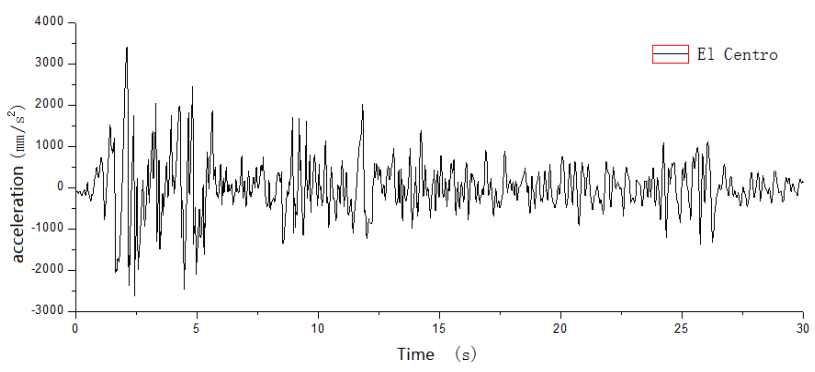

Fig. 4. El Centro wave

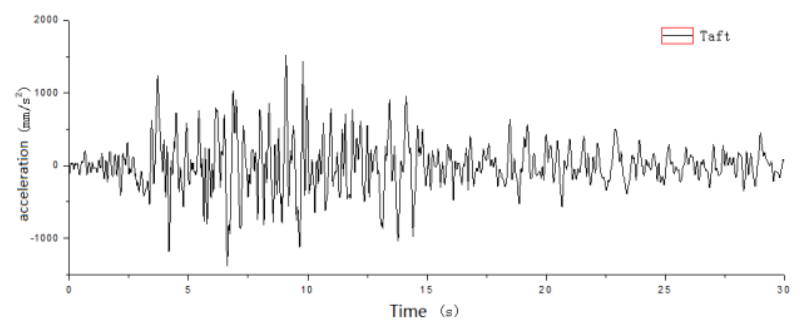

Fig. 5. Taft wave

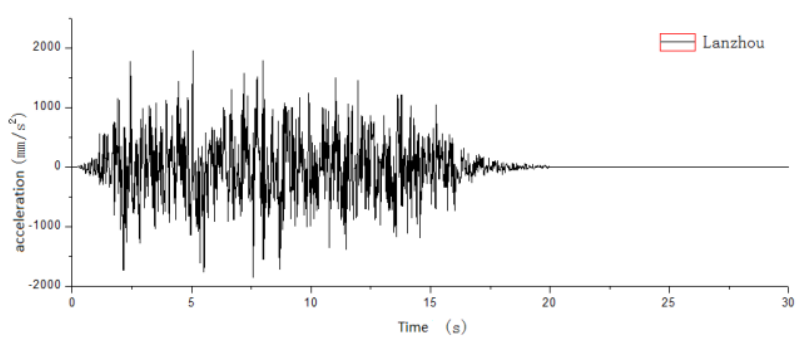

Fig. 6. Lanzhou artificial wave

By comparing the story displacements under different seismic waves, different structures under the same seismic waves are analysed. Figure 7-12 shows the story displacement of different structural models.

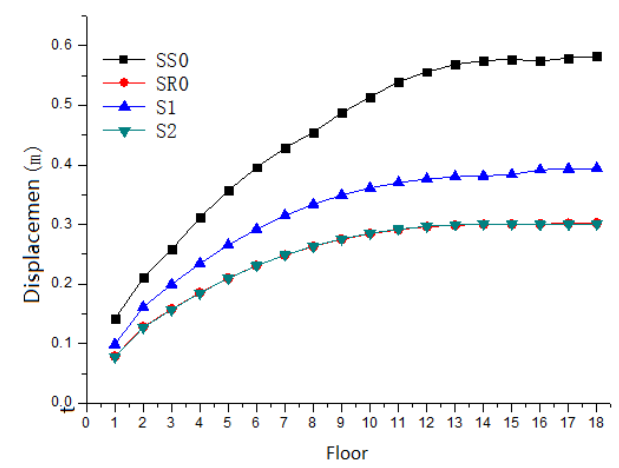

Fig. 7. X-direction story displacement under El Centro wave

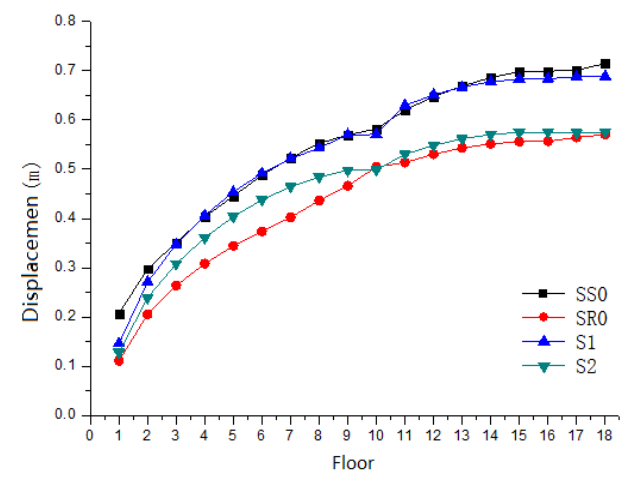

Fig. 8. Y-direction story displacement under El Centro wave 


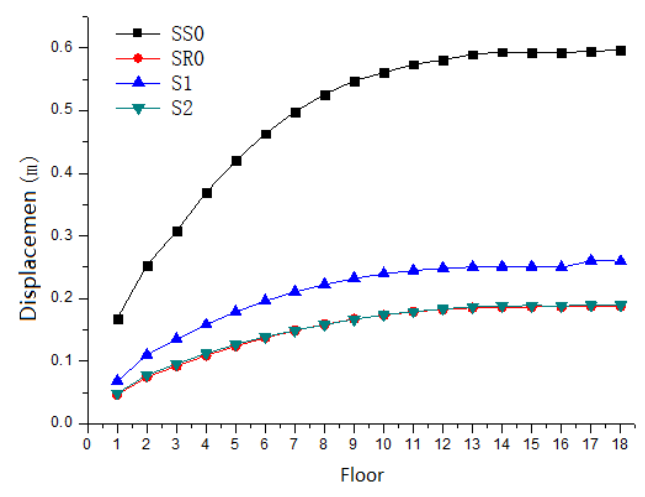

Fig. 9. X-direction story displacement under Taft wave

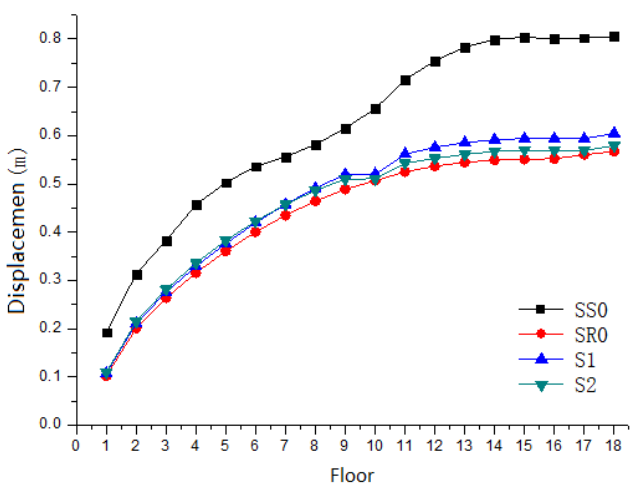

Fig. 10. Y-direction story displacement under Taft wave

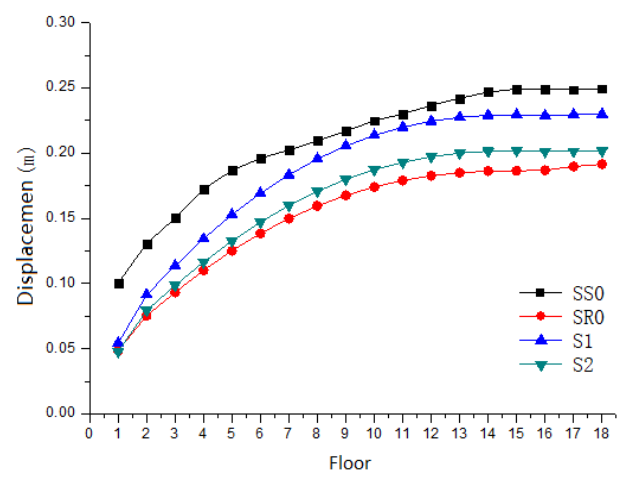

Fig. 11. X-direction story displacement under Lanzhou wave

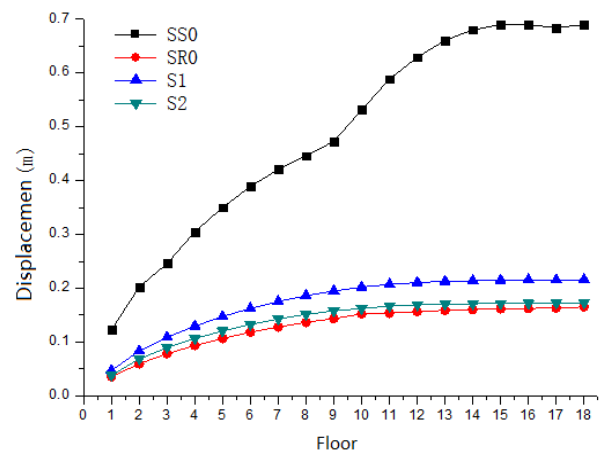

Fig. 12. Y-direction story displacement under Lanzhou wave
It can be seen that the story displacement trend of the four models is similar. The story displacement in the $\mathrm{X}$ direction changes smoothly, while the change in the $\mathrm{Y}$ direction fluctuates more. However, after the adoption of composite lattice column, the story displacement of the model has been reduced significantly. In the two composite lattice column frame, S2 has a greater reduction in story displacement than $\mathrm{S} 1$. S2 can improve the lateral stiffness effectively and adjust the $\mathrm{X}$ and $\mathrm{Y}$ direction stiffness.

The top displacement and vertex acceleration time history curves of different models under the same seismic wave are compared, as shown in Figure 13-18.

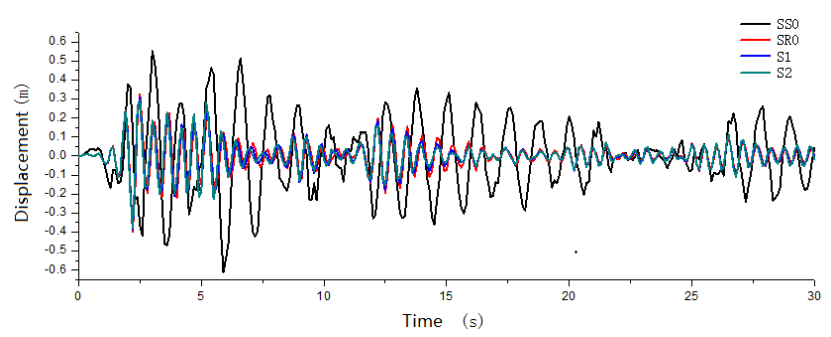

Fig. 13. Top displacement under El Centro wave

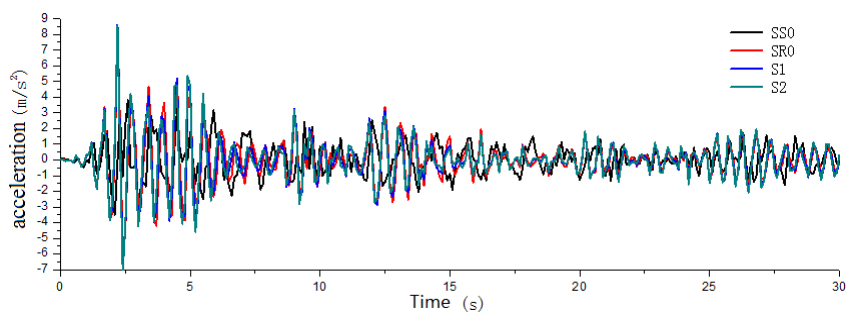

Fig. 14. Vertex acceleration under El Centro wave

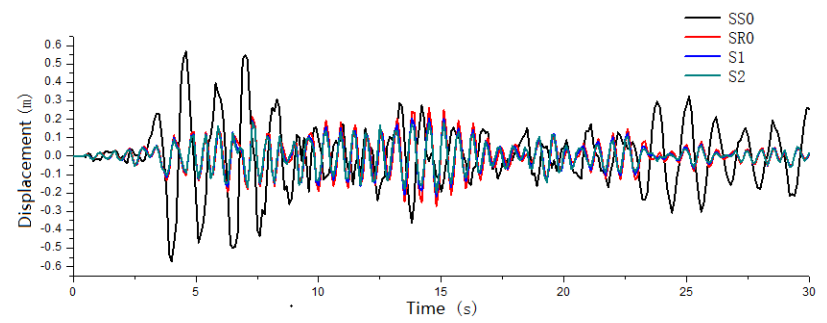

Fig. 15. Top displacement under Taft wave

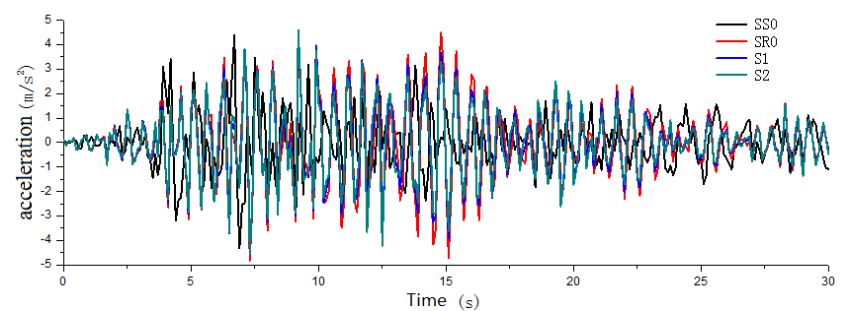

Fig. 16. Vertex acceleration under Taft wave 


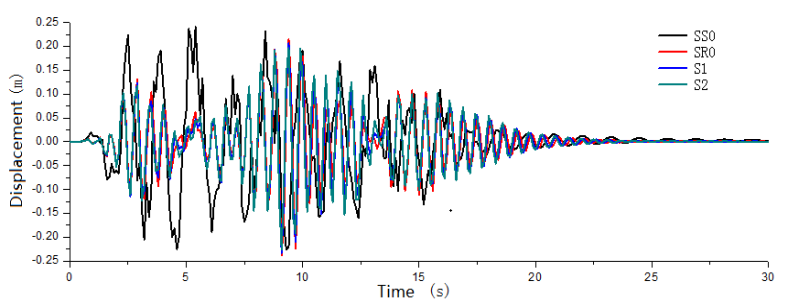

Fig. 17. Top displacement under Lanzhou wave

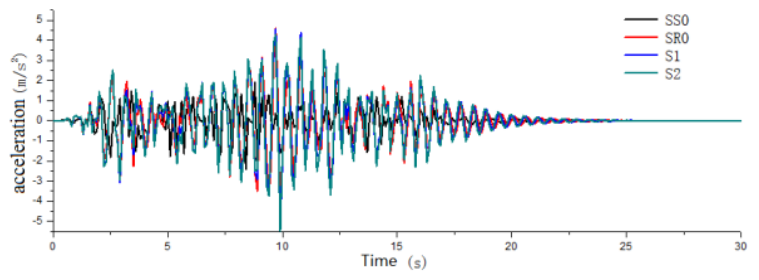

Fig. 18. Vertex acceleration under Lanzhou wave

In summary, the structure will produce different top displacement and vertex acceleration under the different seismic waves. For the top displacement, the peak appears in the first $15 \mathrm{~s}$. In the period of $15 \mathrm{~s} \sim 30 \mathrm{~s}$, the time-history curve fluctuates in a similar cyclic state, and each cycle gradually decays. Under the three kinds of seismic waves, the time-history curve peak of SS0 structure is significantly higher than that of SR0, S1 and S2 structure. The waveform of SR0, S1 and S2 structure is relatively gentle, and the peak appears later, generally within the time period of $5 \mathrm{~s}-15 \mathrm{~s}$. As for the vertex acceleration, it can be seen that the peak of the timehistory curve of $\mathrm{S} 1$ and $\mathrm{S} 2$ is close to the SR0. This indicates that $\mathrm{S} 2$ has better energy dissipation capacity and reduces the displacement of the structure. S2 increases the stiffness, which is beneficial to the seismic resistance of the structure.

\section{Conclusions}

The seismic performance of SLCF was studied through time history analysis, and the following conclusions were drawn:

(1) SLCF has the better strength among the two steel-concrete composite lattice column models, which is about $31.78 \%$ higher than steel composite lattice column frame.

(2) The stiffness of SLCF is close to concrete-core tube structure of the same section. The story displacement trend of the same structure under the different seismic waves is basically identical. This indicates that the SLCF can improve the lateral stiffness effectively and avoid premature torsion of the structure.

(3) The peak of the top displacement time-history curve of steel frame - core tube structure is higher than that of steel composite lattice column frame, SLCF and concrete-core tube structure. The vertex acceleration of steel composite lattice column frame and SLCF is greater than steel frame - core tube structure. The peak of SLCF is the largest, which is close to concrete-core tube structure. The results show that SLCF has better energy dissipation capacity, which improves the structural safety.

\section{Acknowledgments}

The work was sponsored by Natural Science Foundation of Shandong Province (ZR2019MEE009), Ministry of Education University-Industry Collaborative Education Program (201802276002; 201902204001; 201902204002) and Science and Technology Project of Housing and Urban-Rural Development of Shandong Province (2020-K2-3). The writers gratefully acknowledge all the support provided.

\section{References}

1. Zhu, Y.H., (2015) On application of steel structures in high-rise building. Shanxi Architecture, 27: 59-60.

2. Guan, K.J., Peng, S.M. (2001) Application of high rise steel structure in china and existing problems in development. Steel structure, 06: 36-38.

3. Charles, L., (1985) Sparely connected built-up columns. Journal of Structural Engineering, 3: 609627.

4. Kawano, A. Sakinok. (2003) Seismic resistance of CFT trusses. Engineering Structures, 25: 607-619.

5. Akihiko, K., Chiaki, M. (2000) Cyclic local buckling and fracture of concrete filled tubular members. In: Proceedings of the Conference: Composite Construction in Steel and Concrete IV. Banff. 632-643.

6. Akihiko, K., Chiaki M. (2000) The deformation capacity of trusses with concrete filled tubular chords. In: Proceedings of the Conference: Composite Construction in Steel and Concrete IV. Banff. 734-745.

7. Akihiko, K., Kenji, S., Kyoko, K., Kozo, N. (2002) Seismic Resistant System of Multi-Story Frames Using Concrete-Filled Tubular Trusses. In: International Society of Offshore and Polar Engineers. Cupertino. 89-96.

8. Kawano, A., Sakino, K. (2003) Seismic resistance of CFT trusses. Engineering Structures. 5: 607-619. 